\title{
Efficacy and Safety of Miglitol: Switching Study from Voglibose in Japanese Patients with Type 2 Diabetes
}

\author{
Sachiko Honjo ${ }^{1}$, Hiroki Ikeda ${ }^{*}, 1$, Yukiko Kawasaki ${ }^{1}$, Yoshiharu Wada ${ }^{1}$, Yoshiyuki Hamamoto ${ }^{2}$, \\ Tomohisa Aoyama ${ }^{1}$, Tetsuya Kimura ${ }^{1}$, Kazuhiro Nomura ${ }^{1}$ and Hiroyuki Koshiyama ${ }^{1}$ \\ ${ }^{I}$ Center for Diabetes and Endocrinology, the Tazuke Kofukai Medical Research Institute Kitano Hospital, Japan \\ ${ }^{2}$ Department of Diabetes \& Clinical Nutrition, Graduate School of Medicine, Kyoto University, Japan
}

\begin{abstract}
We investigated the efficacy and safety of miglitol, a new alpha-glucosidase inhibitor, by switching from voglibose in Japanese patients with type 2 diabetes. Subjects included those who had previously been administered with voglibose ( $\mathrm{n}=90,0.6 \mathrm{mg} /$ day). After voglibose was changed into miglitol $(150 \mathrm{mg} /$ day $), \mathrm{HbA}_{1 \mathrm{C}}$ level, body weight and abdominal symptoms were evaluated six months later. $\mathrm{HbA}_{1 \mathrm{C}}$ level was significantly decreased from $7.8 \pm 1.2$ to $7.3 \pm 1.0 \%$ $(\mathrm{P}<0.01)$. Body weight showed a small but significant decrease after 6 months $(62.5 \pm 11.0$ to $62.1 \pm 12.3 \mathrm{~kg}, \mathrm{P}<0.01)$. There was no significant difference between frequencies of side effects before and after switching from voglibose to miglitol. This study suggests the efficacy and safety of miglitol to improve glycemic control in Japanese patients with type 2 diabetes, who had previously been treated with voglibose.
\end{abstract}

Several recent studies have suggested that the clinical significance of postprandial hyperglycemia in relation to the risk of microvascular and macrovascular complications [1]. In 2007, International Diabetes Federation has announced the guideline which claimed that postprandial glucose should be less than $140 \mathrm{mg} / \mathrm{dl}[2]$.

Miglitol is a new alpha-glucosidase inhibitor ( $\alpha-\mathrm{GI})$, which has recently been approved for clinical use in Japan. A distinctive feature of miglitol is that it is partially absorbed from the upper portion of the small intestine, thereby making it possible to administer in large doses. Although there have been several preliminary reports about the effects of miglitol on glycemic control [3], there has been no study which compares the clinical effects of miglitol and other $\alpha$-GIs.

In the present study, we investigated the efficacy and safety of miglitol by switching from voglibose, another $\alpha$ GI, which has broadly been used in Japanese patients with type 2 diabetes. Subjects included a total of 90 Japanese patients with type 2 diabetes (54 men and 36 women, mean age $66.5 \pm$ SD10.9 years), who had previously been administered with voglibose $(0.6 \mathrm{mg} /$ day $)$. In all subjects, voglibose was changed into miglitol $(150 \mathrm{mg} /$ day $)$. Serum $\mathrm{HbA}_{1 \mathrm{C}}$ level, plasma postprandial C-peptide level (2 h after the meal), body weight and abdominal symptoms were evaluated before and 6 months after switching from voglibose to miglitol. The data was expressed as mean $\pm \mathrm{SD}$. Statistical analysis was performed with Student's $t$ test between the two groups. Differences were defined as significant at $P<0.05$.

*Address correspondence to this author at the Center for Diabetes \& Endocrinology, Medical Institute Kitano Hospital, 2-4-20 Ohgi-machi, Kitaku Osaka, 530-8480, Japan; Tel: +81-6-6312-8824; Fax: +81-6-6361-8867; E-mails: hirk0913@yahoo.co.jp, a-ikeda@kitano-hp.or.jp
As a result, serum $\mathrm{HbA}_{1 \mathrm{C}}$ level was significantly decreased after 6 months from $7.8 \pm 1.2$ to $7.3 \pm 1.0 \%$ $(\mathrm{P}<0.01)$. There were a relatively great variation in changes of $\mathrm{HbA}_{1 \mathrm{C}}$ among individuals; a decrease in $\mathrm{HbA}_{1 \mathrm{C}}$ was $>1 \%$ in $23 \%$ patients. Postprandial plasma C-peptide did not show any significant change $(2.39 \pm 1.61$ to $2.39 \pm 1.67 \mathrm{ng} / \mathrm{ml})$. Body weight and body mass index showed a small but significant decrease $(62.5 \pm 11.0$ to $62.1 \pm 12.3 \mathrm{~kg}$ after 6 months, $\mathrm{P}<0.01$, $24.3 \pm 3.0$ to $24.2 \pm 3.1 \mathrm{~kg} / \mathrm{m}^{2}$ after 6 months, $\mathrm{P}<0.05$, respectively). As for side effects, there was no significant difference between the frequencies of flatus and flatulence before and after switching from voglibose to miglitol, but soft stool became evident in $12.4 \%$ of the subjects after switching, and three cases of them (3\%) had to stop miglitol because of diarrhea.

Fujisawa et al. reported that there were significantly positive correlation between the efficacy and the side effects of $\alpha$-GI [4]. However, in this study, we did not find any correlation between them. Although there have been no English literature, which compared miglitol to voglibose, it appears that miglitol $(50 \mathrm{mg}$, tid) induces a larger decrease in $\mathrm{HbA}_{1 \mathrm{C}}$ than voglibose $(0.2 \mathrm{mg}$, tid $)$ [5]. It is plausible that miglitol may activate secretion of glucagon-like peptiede-1 (GLP-1), one of incretins, which may help to suppress appetite and thereby to stabilize glycemic control and body weight in obese patients with type 2 diabetes $[6,7]$.

This study suggests that miglitol improves glycemic control and is relatively well tolerated in Japanese patients with type 2 diabetes, who had previously been administered with voglibose.

\section{REFERENCES}

[1] Chiasson JL, Josse RG, Gomis R, et al. Acarbose treatment and the risk of cardiovascular disease and hypertension in patients with impaired glucose tolerance: the STOP-NIDDM trial. JAMA 2003; 290: 486-94. 
[2] International Diabetes Federation: Guidline for Management of Postmeal Glucose. 2007. Available at: www.idf.org

[3] Drent ML, Tollefsen AT, van Heusden FH, et al. Dose-dependent efficacy of miglitol, an a-glucosidase inhibitor, in type 2 diabetic patients on diet alone: Results of a 24-week double-blind placebocontrolled study. Diabetes Nutr Metab 2002; 15: 152-9.

[4] Fujisawa $\mathrm{T}$, Ikegami $\mathrm{H}$, Inoue $\mathrm{K}$, et al. Effect of two a-glucosidase inhibitors, voglibose and acarbose, on postprandial hyperglycemia correlates with subjective abdominal symptoms. Metabolism 2005; 54: $387-90$.
[5] van de Laar FA, Lucassen PL, Akkermans RP, et al. Alphaglucosidase inhibitors for patients with type 2 diabetes: results from a Cochrane systematic review and meta-analysis. Diabetes Care 2005; 28: 154-63.

[6] Lee A, Patrick P, Wishart J, et al. The effects of miglitol on glucagon-like peptide-1 secretion and appetite sensation in obese type 2 diabetes. Diabetes Obes Metab 2002; 4: 329-35.

[7] Narita T, Katsuura Y, Sato T, et al. Miglitol induces prolonged and enhanced glucagon-like peptide-1 and reduced gastric inhibitory polypeptide responses after ingestion of a mixed meal in Japanese type 2 diabetic patients. Diabet Med 2009; 26: 187-8.

(C) Honjo et al.; Licensee Bentham Open.

This is an open access article licensed under the terms of the Creative Commons Attribution Non-Commercial License (http://creativecommons.org/licenses/by-nc/3.0/) which permits unrestricted, non-commercial use, distribution and reproduction in any medium, provided the work is properly cited. 